\title{
Endoscopic Ultrasound-Guided Pancreatic Duct Drainage: Techniques and Literature Review of Transmural Stenting
}

\author{
Akira Imoto ${ }^{1,2}$, Takeshi Ogura ${ }^{2}$ and Kazuhide Higuchi ${ }^{2}$ \\ ${ }^{1}$ Aoyama Hospital, Fujiidera, Osaka, ${ }^{2}$ Second Department of Internal Medicine, Osaka Medical College, Takatsuki, Osaka, Japan
}

Endoscopic ultrasound-guided pancreatic duct drainage (EUS-PD) has emerged as an option in patients with failure of retrograde access to the pancreatic duct (PD) because of difficulty in cannulation or surgically altered anatomy. This article provides a comprehensive review of the techniques and outcomes of EUS-PD, especially EUS-guided pancreatic transmural stenting. The clinical data derived from a total of 401 patients were reviewed in which the overall technical and clinical success rates were $339 / 401$ (85\%, range 63\%-100\%) and 328/372 (88\%, range 76\%-100\%), respectively. Short-term adverse events occurred in 25\% (102/401) of the cases, which included abdominal pain $(n=45)$, acute pancreatitis $(n=17)$, bleeding $(n=10)$, and issues associated with pancreatic juice leakage such as perigastric or peripancreatic fluid collection $(n=9)$. In conclusion, although EUS-PD remains a challenging procedure with a high risk of adverse events such as pancreatic juice leakage, perforation, and severe acute pancreatitis, the procedure seems to be a promising alternative for PD drainage in patients with altered anatomy or unsuccessful endoscopic retrograde pancreatography. Clin Endosc 2020;53:525-534

Key Words: Drainage; Endoscopic ultrasound; Pancreatic; Post-surgery; Stent

\section{INTRODUCTION}

Endoscopic ultrasound-guided pancreatic duct drainage (EUS-PD) is considered as a feasible alternative to surgical or percutaneous drainage in patients with pancreatic ductal (PD) obstruction in whom endoscopic retrograde pancreatography (ERP) has been unsuccessful. Initially described in $2002,{ }^{1}$ EUS-PD can be divided into two distinct techniques, namely, EUS-guided pancreatic transmural stenting (EUSPTS) and rendezvous (EUS-RV). EUS-PD facilitates access to the main PD (MPD) and deploys a stent transmurally (EUSPTS). However, when the duodenoscope can be advanced to

Received: June 25, 2020 Revised: July 31, 2020

Accepted: August 22, 2020

Correspondence: Takeshi Ogura

Second Department of Internal Medicine, Osaka Medical College, 2-7 Daigakumachi, Takatsuki-shi, Osaka 569-8686, Japan

Tel: +81-726-83-1221; Fax: +81-726-84-6423, E-mail: oguratakeshi0411@yahoo. co.jp

ORCID: https://orcid.org/0000-0003-2916-6568

(cc) This is an Open Access article distributed under the terms of the Creative Commons Attribution Non-Commercial License (http://creativecommons.org/ licenses/by-nc/3.0) which permits unrestricted non-commercial use, distribution, and reproduction in any medium, provided the original work is properly cited. the level of the ampulla, it is preferable to attempt an EUS-RV. EUS-RV enables ERP by puncturing the MPD transmurally and advancing the guidewire in an antegrade manner up to the duodenum. While many reports have described the EUS$\mathrm{PD}$ procedure, there is no universal consensus on the optimal strategy to perform EUS-PD. This review focuses on the current status, indications, techniques, and outcomes of EUS-PD, especially EUS-PTS.

\section{INDICATIONS FOR ENDOSCOPIC ULTRASOUND-GUIDED PANCREATIC DUCT DRAINAGE}

The possible indications for EUS-PD are shown in Table 1. Generally, difficulty in transpapillary treatment and lack of a proper approach to the major papilla owing to a reconstructed intestinal tract post-operation are considered as major indications for EUS-PD. The most common underlying diseases are chronic pancreatitis and stenotic pancreaticojejunostomy. ${ }^{2-6}$ In addition, rare diseases such as MPD rupture after acute pancreatitis or trauma, pancreatic cancer, and cholangiocarcinoma 
Table 1. Indications for Endoscopic Ultrasound-Guided Pancreatic Duct Drainage

Indications

MPD dilation caused by strictures or stones

Inaccessible to pancreaticojejunal anastomosis

Difficulty in accessing MPD by ERCP

MPD disruption

Contraindications

Unable to visualize MPD on EUS

Multifocal MPD strictures

Presence of blood vessels interning in the puncture route

Long distance from puncture site to MPD

Coagulopathy, bleeding tendency

ERCP, endoscopic retrograde cholangiopancreatography; EUS, endoscopic ultrasound; MPD, main pancreatic duct. have also been reported. ${ }^{3,5}$ Uchida et al. studied the outcomes of EUS-PD for benign and malignant pancreatic strictures separately. The technical success rates for benign and malignant strictures were $75 \%(6 / 8)$ and $100 \%$ (7/7), respectively, while the adverse event rates were $38 \%(3 / 8)$ and $14 \%(1 / 7)$, respectively. The authors stated that obstructive pancreatitis associated with a pancreatic tumor is an indication for EUSPD. Since the indications for EUS-PD remain controversial, careful case selection is required for implementation of the procedure.

Table 2. Summary of Endoscopic Ultrasound-Guided Pancreatic Transmural Stenting Studies Including at least 20 Cases

\begin{tabular}{|c|c|c|c|c|c|c|c|c|c|}
\hline Study & $\begin{array}{l}\text { Pa- } \\
\text { tients } \\
(n)\end{array}$ & Access route & $\begin{array}{l}\text { Punc- } \\
\text { ture } \\
\text { needle } \\
(G)\end{array}$ & Dilation device & $\begin{array}{l}\text { Kinds of } \\
\text { stents }\end{array}$ & $\begin{array}{l}\text { Tech- } \\
\text { nical } \\
\text { suc- } \\
\text { cess }\end{array}$ & $\begin{array}{l}\text { Clin- } \\
\text { ical } \\
\text { suc- } \\
\text { cess }\end{array}$ & $\begin{array}{l}\text { Ad- } \\
\text { verse } \\
\text { events }\end{array}$ & Details of adverse events ( $n$ ) \\
\hline $\begin{array}{l}\text { Tessier et al. } \\
(2007)^{3}\end{array}$ & 36 & $\begin{array}{l}\text { Stomach (29) } \\
\quad \text { Bulb (7) }\end{array}$ & 19,22 & $\begin{array}{l}\text { Diathermic } \\
\text { dilator }\end{array}$ & 6 or 7 Fr PS & $\begin{array}{c}92 \% \\
(33 / 36)\end{array}$ & $\begin{array}{c}76 \% \\
(25 / 33)\end{array}$ & $\begin{array}{c}14 \% \\
(5 / 36)\end{array}$ & $\begin{array}{c}\text { Hematoma (1), pancreatitis (1), } \\
\text { unspecified complication (3) }\end{array}$ \\
\hline $\begin{array}{l}\text { Fujii et al. } \\
(2013)^{8}\end{array}$ & 43 & Not discussed & 19 & $\begin{array}{l}\text { Balloon, ta- } \\
\text { pered catheters, } \\
\text { needle-knife }\end{array}$ & $\begin{array}{c}\text { Pig or straight } \\
\text { PS }\end{array}$ & $\begin{array}{c}74 \% \\
(32 / 43)\end{array}$ & $\begin{array}{c}93 \% \\
(27 / 29)\end{array}$ & $\begin{array}{c}37 \% \\
(16 / 43)\end{array}$ & $\begin{array}{l}\text { Abdominal pain (13), abscess } \\
\text { (1), guidewire shaving (1), } \\
\text { pancreatitis (1) }\end{array}$ \\
\hline $\begin{array}{l}\text { Will et al. } \\
(2015)^{7}\end{array}$ & 83 & Not discussed & 19 & $\begin{array}{l}\text { Balloon, ring- } \\
\text { knife }\end{array}$ & $\begin{array}{l}\text { Pig or straight } \\
\text { PS }(5-10 \\
\text { Fr), covered } \\
\text { SEMS, LAMS } \\
\text { (AXIOS) }\end{array}$ & $\begin{array}{c}63 \% \\
(52 / 83)\end{array}$ & $\begin{array}{c}82 \% \\
(68 / 83)\end{array}$ & $\begin{array}{c}29 \% \\
(24 / 83)\end{array}$ & $\begin{array}{l}\text { Pancreatitis (6), bleeding (6), } \\
\text { abscess (4), perigastric fluid } \\
\text { (3), ulcer (2), aspiration (1), } \\
\text { perforation (1), retention cyst } \\
\text { (1) }\end{array}$ \\
\hline $\begin{array}{l}\text { Oh et al. } \\
(2016)^{29}\end{array}$ & 25 & $\begin{array}{l}\text { Stomach (23) } \\
\text { Bulb (1) } \\
\text { Jejunum (1) }\end{array}$ & 19 & $\begin{array}{l}\text { Balloon, nee- } \\
\text { dle-knife }\end{array}$ & $\begin{array}{c}\text { Modified } \\
\text { covered SEMS }\end{array}$ & $\begin{array}{c}100 \% \\
(25 / 25)\end{array}$ & $\begin{array}{c}100 \% \\
(25 / 25)\end{array}$ & $\begin{array}{c}20 \% \\
(5 / 25)\end{array}$ & $\begin{array}{l}\text { Abdominal pain (4), bleeding } \\
\text { (1) }\end{array}$ \\
\hline $\begin{array}{l}\text { Tyberg et al. } \\
(2017)^{27}\end{array}$ & 80 & Not discussed & 19 & $\begin{array}{l}\text { Cautery, bal- } \\
\text { loon }\end{array}$ & $\begin{array}{l}\text { Pig PS }(5-10 \\
\text { Fr) }\end{array}$ & $\begin{array}{c}89 \% \\
(71 / 80)\end{array}$ & $\begin{array}{c}92 \% \\
(65 / 71)\end{array}$ & $\begin{array}{c}20 \% \\
(16 / 80)\end{array}$ & $\begin{array}{l}\text { Pancreatitis (6), pancreatic fluid } \\
\text { collection (4), abdominal pain } \\
\text { (3), bleeding (1), MPD leak (1), } \\
\text { perforation (1) }\end{array}$ \\
\hline $\begin{array}{l}\text { Chen et al. } \\
(2017)^{11}\end{array}$ & 37 & Not discussed & 19,22 & Not disc & $\mathrm{DS}$ & $\begin{array}{c}92 \% \\
(34 / 37)\end{array}$ & $\begin{array}{c}85 \% \\
(29 / 34)\end{array}$ & $\begin{array}{c}41 \% \\
(15 / 37)\end{array}$ & $\begin{array}{l}\text { Abdominal pain (13), abscess } \\
\text { (1), ulcer (1) }\end{array}$ \\
\hline $\begin{array}{l}\text { Matsunami } \\
\text { et al. }(2018)^{6}\end{array}$ & 30 & Not discussed & 19,22 & $\begin{array}{l}\text { Balloon, elec- } \\
\text { trocautery dila- } \\
\text { tor, mechanical } \\
\quad \text { dilator }\end{array}$ & $\begin{array}{l}\text { Dedicated PS } \\
\quad(7 \mathrm{Fr})\end{array}$ & $\begin{array}{c}100 \% \\
(30 / 30)\end{array}$ & $\begin{array}{c}100 \% \\
(30 / 30)\end{array}$ & $\begin{array}{l}23 \% \\
(7 / 30)\end{array}$ & $\begin{array}{l}\text { Abdominal pain (5), pancreati- } \\
\text { tis (1), bleeding (1) }\end{array}$ \\
\hline $\begin{array}{l}\text { Oh et al. } \\
(2020)^{2}\end{array}$ & 23 & $\begin{array}{l}\text { Stomach (22) } \\
\text { Jejunum (1) }\end{array}$ & 19 & $\begin{array}{l}\text { Balloon, nee- } \\
\text { dle-knife }\end{array}$ & $\begin{array}{l}\text { Pig PS (7 Fr), } \\
\text { covered SEMS }\end{array}$ & $\begin{array}{c}100 \% \\
(23 / 23)\end{array}$ & $\begin{array}{c}100 \% \\
(23 / 23)\end{array}$ & $\begin{array}{c}17 \% \\
(4 / 23)\end{array}$ & $\begin{array}{l}\text { Abdominal pain (3), peripan- } \\
\text { creatic fluid (1) }\end{array}$ \\
\hline $\begin{array}{l}\text { Dalal et al. } \\
(2020)^{15}\end{array}$ & 44 & $\begin{array}{l}\text { Stomach (41) } \\
\text { Bulb (3) }\end{array}$ & 19,22 & $\begin{array}{l}\text { Balloon, } \\
\text { electrocautery } \\
\text { dilator }\end{array}$ & $\begin{array}{l}\text { Pig or straight } \\
\text { PS (5-7 Fr) }\end{array}$ & $\begin{array}{c}89 \% \\
(39 / 44)\end{array}$ & $\begin{array}{c}82 \% \\
(36 / 44)\end{array}$ & $\begin{array}{c}23 \% \\
(10 / 44)\end{array}$ & $\begin{array}{l}\text { Abdominal pain (4), pancreati- } \\
\text { tis (2), fever (2), bleeding (1), } \\
\text { stripping of guidewire (1) }\end{array}$ \\
\hline
\end{tabular}

LAMS, lumen-apposing metal stent; MPD, main pancreatic duct; PS, plastic stent; SEMS, self-expandable metal stent. 


\section{SUMMARY OF PREVIOUS ENDOSCOPIC ULTRASOUND-GUIDED PANCREATIC TRANSMURAL STENTING STUDIES}

A summary of previous studies of EUS-PTS that evaluated more than 20 cases is shown in Table 2. The total number of patients was 401 , with the largest series comprising 83 patients. The overall technical and clinical success rates were 339/401 (85\%, range $63 \%-100 \%)$ and $328 / 372$ (88\%, range $76 \%-$ $100 \%)$, respectively. The overall short-term adverse events occurred in 25\% (102/401) of the cases. Severe adverse events were observed in 5\% (20/401) of the cases, which included acute pancreatitis $(n=8)$, pancreatic fluid collection $(n=4)$, perforation $(n=2)$, abscess $(n=2)$, bleeding $(n=1)$, hematoma $(n=1)$, pancreatic juice leakage $(n=1)$, and guidewire shaving $(n=1)$. A single case of acute pancreatitis with a pseudocyst and another case of hematoma required additional endoscopic drainage. ${ }^{3}$ Moreover, in an additional case of severe bleeding wherein an electrocautery dilator was used on the patient for tract dilation, transcatheter arterial embolization was required to mitigate the situation. ${ }^{6}$ In one case of perforation, urgent surgical intervention was imperative ${ }^{7}$; while a case of peripancreatic abscess was managed with EUS-guided transmural drainage. ${ }^{8}$ Transection of the guidewire sheath in the retroperitoneum was managed conservatively with observation, with no reported sequelae. ${ }^{8}$ Overall, the technical and clinical success rates associated with the technique have been high. However, it must be noted that the incidence of adverse events is relatively high, and some severe detrimental events did occur.

\section{TECHNICAL SUMMARY OF ENDOSCOPIC ULTRASOUND-GUIDED PANCREATIC DUCT DRAINAGE}

There are two access routes for identifying MPD: transgastric and transduodenal. The puncture site in the stomach is usually in the upper portion. If stomach puncture is challenging, the scope should be placed into the second portion of the duodenum initially and then pulled back to the stomach. This effort might make the puncture easier because the MPD can be identified from around the lower or middle portions of the stomach after this step. There are two types of EUS-PD, EUS-RV and EUS-PTS, and the entire flow of each method is described in this section.

The technical tips for EUS-RV are presented in Fig. 1. The contrast agent is injected after puncturing the MPD (Fig. 1A). Attempts are made to advance the guidewire in an antegrade fashion across the stricture site into the intestine (Fig. 1B). The EUS scope is removed with the guidewire that is left in the place. A duodenoscope is inserted into the level of the ampulla of Vater, and the guidewire is grasped (Fig. 1C). After the guidewire is pulled into the duodenoscope (Fig. 1D), cannulation into MPD and stenting are performed in retrograde fashion (Fig. 1E).

In Fig. 2, the flow of EUS-PTS with a plastic stent has been
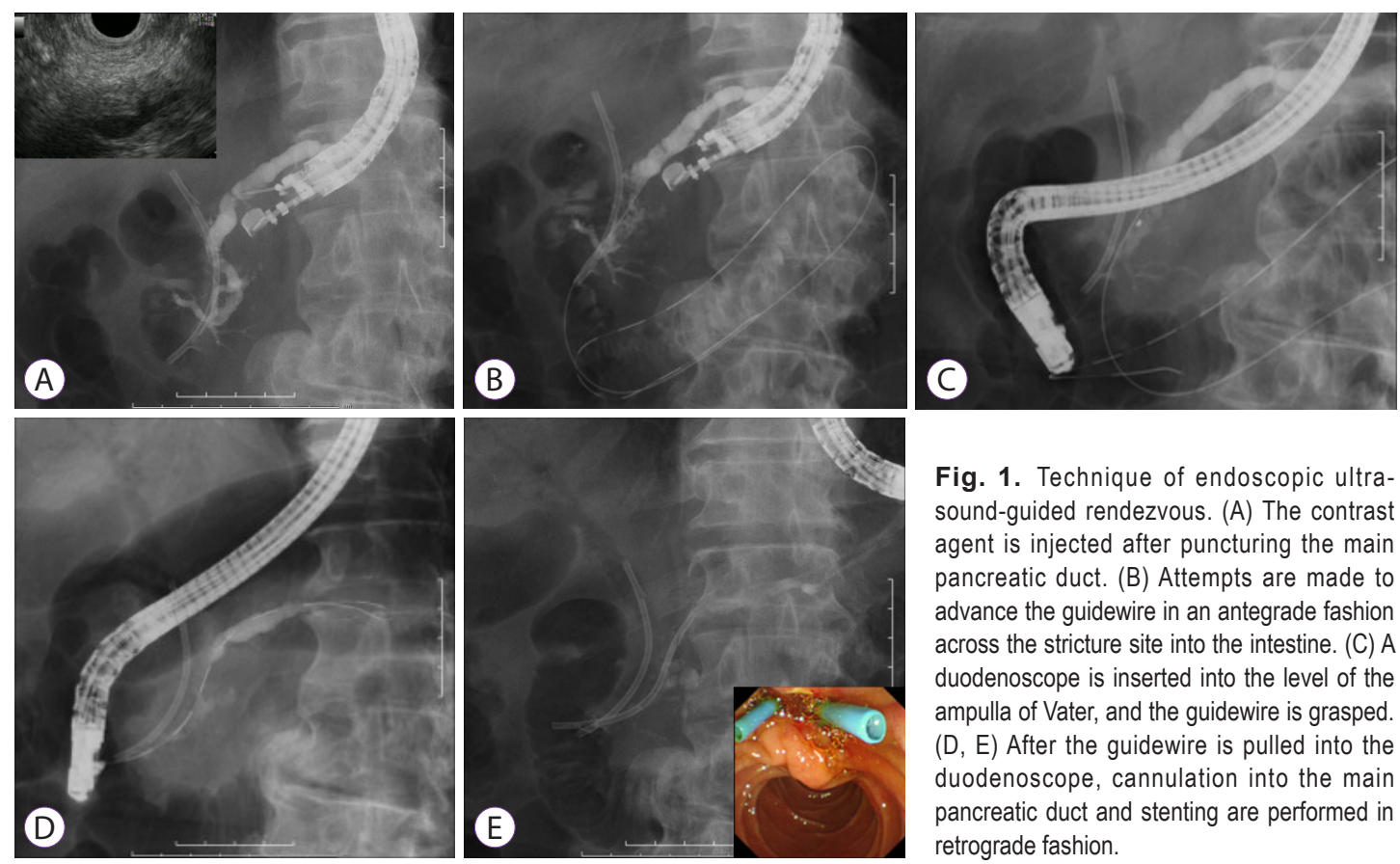

Fig. 1. Technique of endoscopic ultrasound-guided rendezvous. (A) The contrast agent is injected after puncturing the main pancreatic duct. (B) Attempts are made to advance the guidewire in an antegrade fashion across the stricture site into the intestine. (C) A duodenoscope is inserted into the level of the ampulla of Vater, and the guidewire is grasped. $(D, E)$ After the guidewire is pulled into the duodenoscope, cannulation into the main pancreatic duct and stenting are performed in retrograde fashion. 

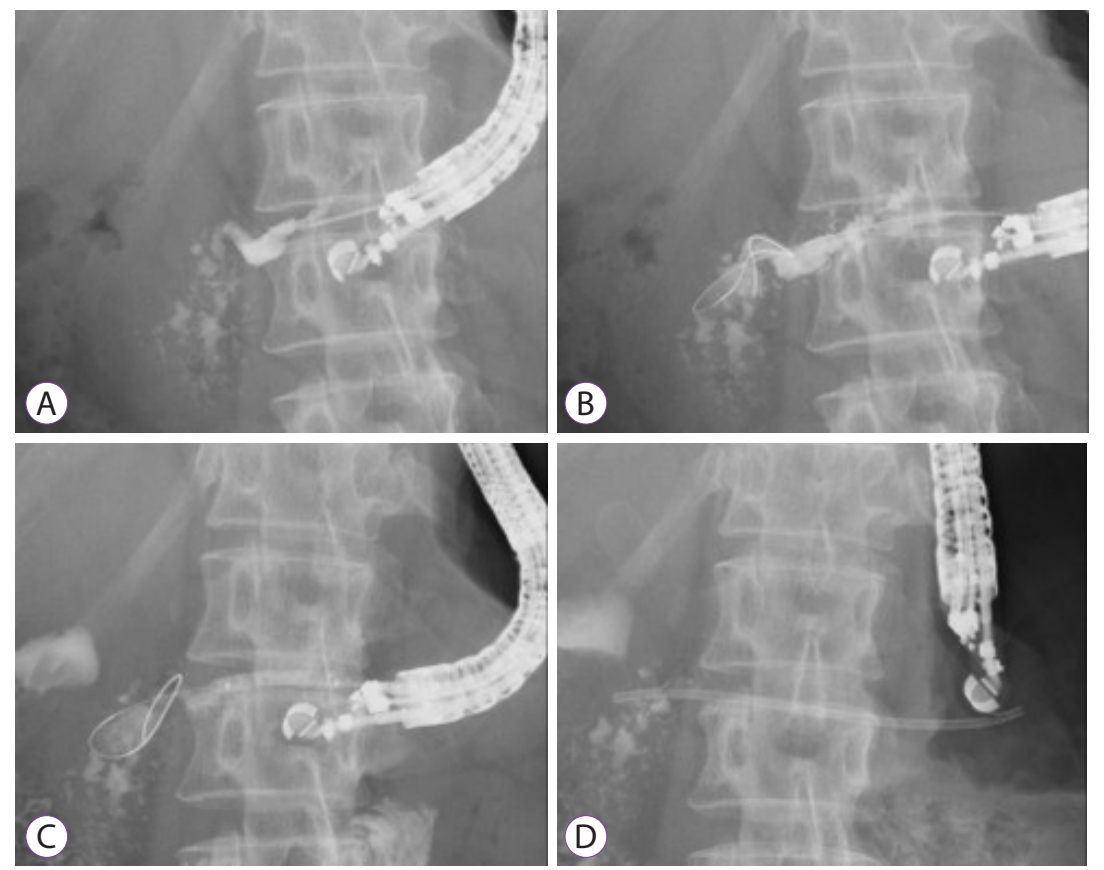

Fig. 2. Technical tips for endoscopic ultrasound-guided pancreatic transmural stenting. (A) The main pancreatic duct is punctured with a 19-G needle and confirmed by injection of contrast medium. (B) A guidewire is advanced into the main pancreatic duct. (C) The tract fistula is dilated using a balloon dilator. (D) Antegrade stent deployment is performed.

depicted. The MPD is confirmed by injection of contrast medium after puncture with a 19-G needle (Fig. 2A). Thereafter, a guidewire is inserted into the MPD (Fig. 2B). Fistula tract dilation is performed by using mechanical dilators, balloon dilators, or electrocautery dilators (Fig. 2C). Furthermore, antegrade stent deployment is performed (Fig. 2D).

\section{TECHNIQUES}

\section{Technical tips for puncture}

The PD is either accessed with a $22-\mathrm{G}$ or $19-\mathrm{G}$ needle. The advantage of using a $22-\mathrm{G}$ needle is that it becomes easy to puncture even a fibrotic pancreas or a stiff MPD $(<5 \mathrm{~mm})$. In fact, Matsunami et al. reported that the reason for their high technical success rate with EUS-PD, despite the small targeted MPD (median MPD diameter $3.5 \mathrm{~mm}$, range 1-14 mm), might be attributed to the use of a $22-\mathrm{G}$ needle. ${ }^{6}$ However, a $22-G$ needle can only use a 0.018 - or 0.021 -inch guidewire, which would have problems in terms of fluoroscopic visibility and sufficient stiffness that can withstand subsequent treatment. Therefore, a 19-G needle, which can accommodate a 0.025- or 0.035-inch guidewire, would be an optimal choice to access the MPD unless the parenchyma of the pancreas is highly fibrotic. Indeed, a 19-G needle was preferred to a
22-G needle in previous reports. Itoi et al. described in detail the needles and the guidewires used in EUS-PD., ${ }^{9,10}$ In their report, a 0.025-inch guidewire "VisiGlide" with an angled tip (Olympus Medical Systems, Tokyo, Japan) was recommended because it had a soft, highly flexible tip with outstanding radiopacity, clear endoscopic visibility, sufficient stiffness at the guidewire shaft, seeking ability for easy therapeutic instrument exchange, and less kinking. In addition, a 0.025-inch and 0.035-inch Jagwire (Boston Scientific, Marlborough, MA, USA), 0.025-inch, 0.032-inch, and 0.035-inch Radifocus (Terumo Co., Tokyo, Japan), 0.035-inch Tracer (Cook Medical, Winston-Salem, NC, USA) for a 19-G needle, 0.018-inch and 0.021-inch Radifocus (Terumo Co.), 0.021-inch Metro (Cook Medical), 0.018-inch Pathfinder (Boston Scientific), and 0.018inch Roadrunner (Cook Medical) for a 22-G needle have also been reported as guidewires for EUS-PD (Table 3). When the 0.018 -inch guidewire or 0.021-inch guidewire is used as the first guidewire, replacement with a large caliber and stiffer guidewire is recommended for subsequent intervention. ${ }^{9-11}$

With respect to the considered parameters for needle selection, the sharpness of the tip is also an important factor along with the needle size. A stiff parenchyma resulting from chronic pancreatitis would prevent a smooth puncture in the absence of a sharp tip. Dhir et al. noted that a curved needle is not suitable for EUS-PD because the PD is thinner than the 
Table 3. Various Guidewires Used in Endoscopic Ultrasound-Guided Pancreatic Duct Drainage

\begin{tabular}{|c|c|c|c|}
\hline Product name & Size (inch) & Manufacturer & References \\
\hline \multicolumn{4}{|l|}{ For 19-G needle } \\
\hline VisiGlide/VisiGlide2 & 0.025 & Olympus Medical Systems, Tokyo, Japan & $2,5,6,9,10,12,15,18,22,29$ \\
\hline Jagwire & $0.025,0.035$ & Boston Scientific, Marlborough, MA, USA & $3,7,8$ \\
\hline Radifocus & $0.025,0.032,0.035$ & Terumo Co., Tokyo, Japan & $9,12,15$ \\
\hline Tracer & 0.035 & Cook Medical, Winston-Salem, NC, USA & 29 \\
\hline \multicolumn{4}{|l|}{ For 22-G needle } \\
\hline Radifocus & $0.018,0.021$ & Terumo Co. & 9 \\
\hline Metro & 0.021 & Cook Medical & 6,18 \\
\hline Pathfinder & 0.018 & Boston Scientific & $6,15,18$ \\
\hline Roadrunner & 0.018 & Cook Medical & 4 \\
\hline
\end{tabular}

bile duct. ${ }^{12}$ They preferred a Sono-tip (MediGlobe GmbH, Achenmuhle, Germany) for chronic pancreatitis cases due to its sharpness and bendability. In addition, it has been reported that needles such as the $22 \mathrm{G} / 19$ G Echo Tip (Cook Medical), 19 G Expect (Boston Scientific), and 19 G EZ shot 2/3 (Olympus Medical Systems) were used for EUS-PD.

The puncture site for EUS-PD is either transgastric or transduodenal. When selecting the puncture site, it is necessary to comprehensively judge the puncture angle to the MPD, where the blood vessel passes, and the distance from the stenosis. A transduodenal approach from the "long position" might allow a better view of the MPD for puncture than the transgastric approach. ${ }^{3,13}$ Moreover, intraoperative stability and ease of pushing the stent were also reported as advantages associated with the transduodenal approach. However, in a transduodenal puncture, it might be difficult to pass through the stenosis of the guidewire when the stenosis is in the pancreatic body. In addition, care should be taken for the gastroduodenal artery running near the puncture route from the duodenal bulb, as it can be injured due to the burning effects of electrocautery dilation..$^{13}$ Although previous reports seem to indicate that there is currently no difference in the technical and clinical perspectives by either route, a substantial number of available studies had selected the transgastric route. Overall, both transgastric and transduodenal routes are acceptable, but it is better to attempt puncturing from a site with better conditions.

\section{Technical tips for fistula dilation}

In EUS-PD, dilation of the gastric wall, pancreatic parenchyma, and MPD is challenging. For subsequent stent deployment, this step should be attempted. To obtain successful fistula dilation, guidewire manipulation is also important. The guidewire should be advanced deep enough for the rigid part to reach inside the MPD to ensure safe procedures afterward. An important aspect of this step in the case of a fibrotic and hardened pancreas is to efficiently apply force in the same direction as the puncture. In order to achieve this, it is necessary to confirm that the shape of the scope is the same as that at the time of puncture on fluoroscopic imaging, while the guidewire is kept visible in the longitudinal direction on ultrasonographic imaging throughout the procedure.

Endoscopic devices for dilating the needle tract are mainly divided into two types, non-electrocautery, and electrocautery. Non-electrocautery devices include mechanical dilators and balloon dilators, whereas electrocautery devices are classified into non-coaxial type and coaxial type. The main dilation devices that are currently used in EUS-PD are summarized in Table 4. Step-up dilation of the needle tract using dilation catheters or balloon catheters for bougies is usually performed up to the size sufficient for stenting. ${ }^{10}$ Itoi et al. mentions the use of a tapered catheter (endoscopic retrograde cholangiopancreatography [ERCP] catheter; MTW Co., Dusseldorf, Germany) for the first bougie, followed by a 5-7 Fr dilation catheter (Soehendra; Cook Medical) or balloon catheters or the Cysto-Gastro Set (Endo-Flex, Voerde, Germany) in the subsequent steps. ${ }^{9,10}$

With respect to the use of balloon catheters, we have previously shown the usefulness of a fine-gauge balloon catheter REN (KANEKA Medics, Osaka, Japan) for EUS-PD (Fig. 3). ${ }^{14}$ This catheter was characterized by a $3 \mathrm{Fr}$ ultra-tapered tip and coaxial guidewire followability. Hayat et al. reported a retrospective study of EUS-PD using a small-caliber balloon (Sterling; Boston Scientific) in eight patients. ${ }^{4}$ This balloon catheter was originally designed for use in angioplasty and had only a $4 \mathrm{Fr}$ diameter. The technical success rate with dilation using only this small-diameter balloon was $88 \%$ (7/8). In the 
Table 4. Dilation Devices for the Fistula in Endoscopic Ultrasound-Guided Pancreatic Duct Drainage

\begin{tabular}{|c|c|c|c|}
\hline Device & Product name & Manufacturer & References \\
\hline \multicolumn{4}{|l|}{ Non-electrocautery } \\
\hline \multirow[t]{6}{*}{ Mechanical dilator } & ERCP catheter & MTW Co., Dusseldorf, Germany & $9,10,12$ \\
\hline & RR-V220Q ERCP catheter & Olympus Medical Systems, Tokyo, Japan & 5 \\
\hline & ProForma ERCP catheter & ConMed Endoscopic Technologies, Utica, NY, USA & 8,22 \\
\hline & Sohendola stent retriever & Cook Medical, Winston-Salem, NC, USA & $8,9,10,15,22$ \\
\hline & ES dilator & Zeon Medical Co., Tokyo, Japan & 18 \\
\hline & PD-SS6F180C & Gadelius Medical, Tokyo, Japan & 12 \\
\hline \multirow[t]{5}{*}{ Balloon dilator } & REN & KANEKA Medics, Osaka, Japan & $12,14,18$ \\
\hline & Titan & Cook Medical & 8,22 \\
\hline & Hurricane RX & Boston Scientific, Marlborough, MA, USA & $6,7,8,12,15,18,22,29$ \\
\hline & Sterling & Boston Scientific & 4 \\
\hline & Maxforce TTS & Boston Scientific & \\
\hline \multicolumn{4}{|l|}{ Electrocautery } \\
\hline \multirow[t]{2}{*}{ Non-Coaxial } & NeedleCut 3V & Olympus Medical Systems & 9 \\
\hline & MicroKnife & Boston Scientific & 29 \\
\hline \multirow[t]{4}{*}{ Coaxial } & Fine 025 & Medico's HIRATA Inc., Osaka, Japan & 13,16 \\
\hline & Cyst-Gastro Set & Endo-Flex, Voerde, Germany & $3,6,9,10,12,15,18$ \\
\hline & Cystotome CST10 & Cook Medical & \\
\hline & Will's high frequency ring knife & MTW Co. & 7 \\
\hline
\end{tabular}

ERCP, endoscopic retrograde cholangiopancreatography.

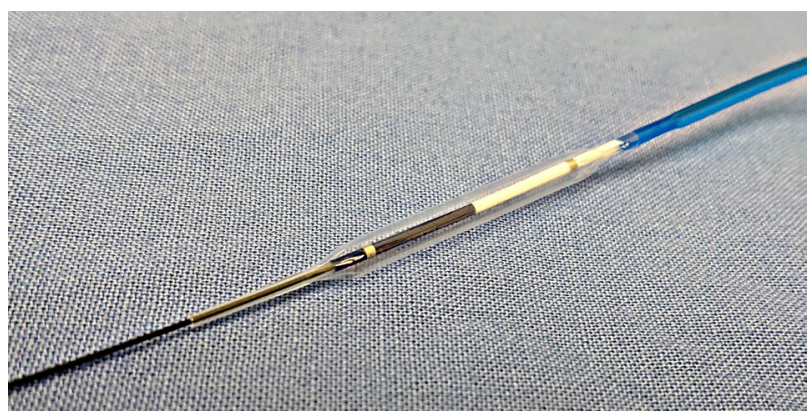

Fig. 3. REN (KANEKA Medics, Osaka, Japan). This balloon catheter is characterized by a $3 \mathrm{Fr}$ ultra-tapered tip and coaxial guidewire followability.

unsuccessful case, the device could not cross the pancreatic parenchyma, and a small leakage in the duct occurred that did not require any additional intervention. The author concluded that the caliber balloon from Sterling offered a safe and atraumatic alternative without the use of a cautery device.

There are some reports on the use of mechanical dilation or electrocautery dilation on a case-specific basis. In a retrospective study evaluating 44 EUS-PD cases, one of the following was used as the dilation method for EUS-PD: a Soehendra stent retriever, a Hurricane RX (Boston Scientific), or a Cysto-Gastro Set. ${ }^{15}$ The authors noted that a Hurricane RX or Cysto-Gastro Set was used for antegrade transmural tract dilation, while the Soehendra stent retriever or Cysto-Gastro Set was used for retrograde transmural tract dilation after rendezvous, respectively. The technical success in this study was $84.1 \%$ (37/44), and the most common cause for failure of the procedure was reported to be an inability to puncture the MPD because of severe fibrosis and calcification in the pancreas. Immediate adverse events were seen in 22.7\% $(n=10)$ of the cases, and they were sufficiently mild to be managed conservatively.

There is a report of a case in which dilation of the needle tract using fine diathermic dilation (Fine 025; Medico's HIRATA Inc., Osaka, Japan; Fig. 4) was successful after dilation with a mechanical dilator (ES dilator; Zeon Medical Co., Tokyo, Japan; Fig. 5) failed due to hard pancreatic parenchyma. ${ }^{16}$ The distal end of a Fine 025 is only $3 \mathrm{Fr}$ and contains a metal tip. This diathermic dilator is coaxial with a guidewire and can be useful for tract dilation in a severely fibrotic pancreas. In addition to its high ability to rupture the tissue, the Fine 025 


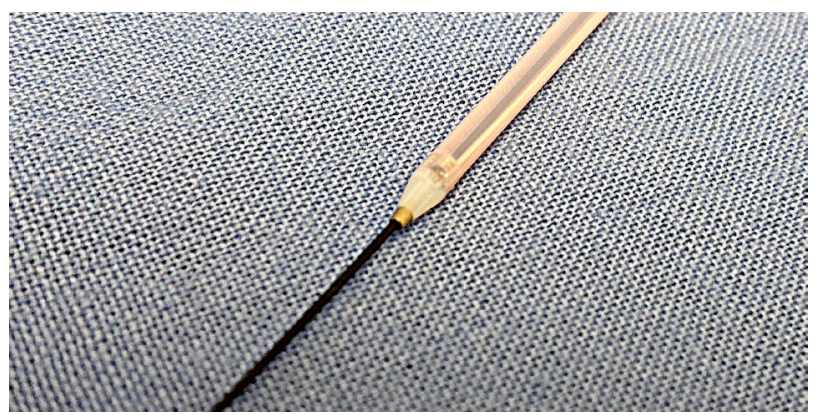

Fig. 4. Fine 025 (Medico's HIRATA Inc., Osaka, Japan). The distal end of this diathermic dilator is only $3 \mathrm{Fr}$, and it contains a metal tip. This catheter is coaxial with a guidewire and can be useful for tract dilation in a severely fibrotic pancreas.

is expected to have the potential to reduce damage to the surrounding regions because of a thin electrode on the tip.

As mentioned above, a mechanical dilator is usually used first to dilate the puncture fistula. ${ }^{5,8-10}$ Although cautery-assisted devices may prove to be more efficacious when pancreatic parenchyma is hardened from fibrosis, ${ }^{17-19}$ their use is limited and is often positioned as a subsequent method when dilation with mechanical devices fail. This is mainly because of the risk of adverse events associated with cautery devices. Indeed, many experts recommend the use of electrocautery devices only as a rescue technique when other approaches fail. ${ }^{17,20-22}$ Dilation with electrocautery catheters in EUS-PD has been reported to be capable of causing acute and late "burn-effects" around the tract, leading to severe adverse events including pancreatitis, pancreatic juice leakage, bleeding, and perforation. ${ }^{9}$ A study comparing the safety of a mechanical dilator and an electrocautery dilator in patients undergoing EUS-hepaticogastrostomy $(n=49)$ and EUS-PD $(n=15)$ showed that there was no significant difference in the rate of adverse events $(16.1 \%$ vs. $27.2 \%, p=0.48)$ between the two groups. ${ }^{18}$ Comparing the reports of adverse events in the literature, procedure-related bleeding was observed only in the electrocautery dilator group ( $0 \%$ vs. $18.2 \%, p=0.04$ ). Therefore, it has been suggested that a mechanical dilator was more suitable for interventional EUS, particularly in patients taking antithrombotic drugs or when the blood vessels were located near the puncture line. Matusnami et al. reported severe bleeding that required transcatheter arterial embolization after dilation using an electrocautery dilator in EUS-PD. ${ }^{6}$ Therefore, they warned that tract dilation using an electrocautery dilator may cause unexpected bleeding due to a burn effect even with the use of Doppler mode, in order to avoid injuring the intervening blood vessels under EUS guidance.

There has been no detailed study that determined the criteria for the selection of non-coaxial or coaxial electrocautery

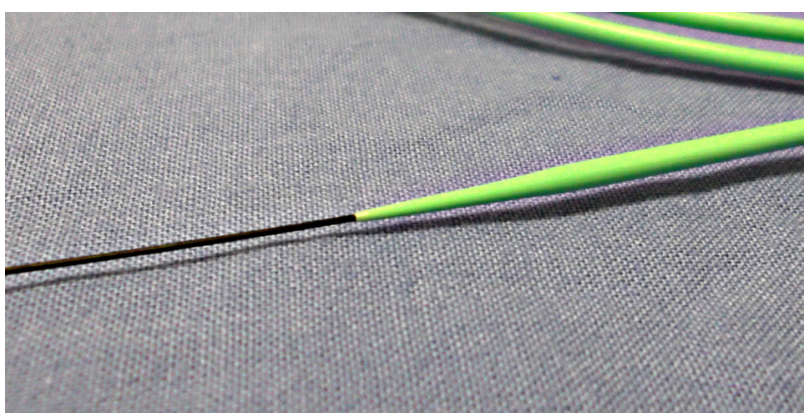

Fig. 5. ES dilator (Zeon Medical Co., Tokyo, Japan). This mechanical dilator can be pushed to a greater degree and exhibits only a small difference in the diameter of the inner lumen and the guidewire.

in EUS-PD. Park et al. studied the predictors of adverse events in 57 patients who underwent EUS-guided biliary drainage (EUS-BD) with transluminal stenting and showed that the use of a cautery-assisted device was an independent predictor of adverse events (odds ratio [OR], 12.4; $p=0.01$ ). ${ }^{23}$ The electrocautery device used in that study was a non-coaxial needle knife. In contrast, a comparative study of mechanical dilation and coaxial electrocautery dilation in EUS-guided pancreatic fluid collection drainage showed no significant difference in the occurrence of adverse events. ${ }^{19}$ Free air was seen as an immediate adverse event in only one case in the non-electrocautery group $(1 / 28)$. Khashab et al. also evaluated the adverse events in patients who underwent EUS-BD $(n=121){ }^{24}$ In that study, non-coaxial and coaxial electrocautery devices were separately analyzed, and only non-coaxial electrocautery was found to be independently associated with adverse events (OR, $3.95 ; p=0.03)$. Especially, when the scope is in an acute angulation position, the non-coaxial type needle-knives are oriented tangentially, leading to undesired incisions and adverse events. ${ }^{22}$ Such a scenario can be prevented by maintaining a degree of tension over the guidewire that would keep the needle-knife catheter in the same plane as the guidewire, as it exits the scope. Even in EUS-PD, the non-coaxial type may require more attention than the coaxial type when using electrocautery devices for dilation.

Non-electrocautery devices also have a risk of adverse events. Catheter dilation was reported to be associated with an axial force, which can lead to the separation of tissue planes during bougie advancement. ${ }^{20}$ In addition, balloon dilation increased the risk of perforation, leakage, and bleeding with its radial force. ${ }^{20}$ According to a study $(n=28)$ that utilized a mechanical dilator including an ES dilator, a 7-Fr tapered catheter, and a 4-mm balloon dilator for EUS-BD, adverse events occurred in four patients (14.3\%, 4 bile peritonitis), ${ }^{25}$ and all patients recovered with conservative drug treatment. We also 
evaluated the feasibility and safety of balloon catheter REN in EUS-BD $(n=20){ }^{26}$ Adverse events were seen in 15\% (3/20; self-limited abdominal pain $n=2$, peritonitis $n=1$ ) of cases in that study. All the cases were mild, and they did not require any additional intervention.

In conclusion, there is still no clear consensus on which devices are to be used first during EUS-PD. However, it seems that non-cautery-assisted devices might be recommended as the primary dilation device as per the available reports. Prospective trials aimed at standardizing the technique for performing dilation in EUS-PTS are necessary to design conclusive models for such procedures.

\section{Technical tips for stent deployment}

Most stents that are reported to be placed transmurally in EUS-PD are plastic stents. ${ }^{4-6,15}$ Both straight and pig tail stents with diameters of 5 to $7 \mathrm{Fr}$ have been frequently used. When plastic stents are selected for EUS-PTS, an "all-in-one stent" is recommended to avoid insertion failure. ${ }^{9}$ The "all-in-one stent" has the advantage of being able to return to the state before stent release when the length of the stent is inappropriate at the time of placement of the stent, or when stent advancement is impossible across the tract. This is possible because of the presence of a string between the stent and the delivery system. As a result of this advantage. different stent placement or additional tract dilation can be carried out when stent insertion is difficult. "Ring drainage" (i.e., gastropancreaticoduodenostomy) has been described as an important technique for preventing the migration in EUS-PTS. ${ }^{1721}$ This procedure can be performed only when the stent is advanced so that the distal end terminates in the small bowel anterogradely, and the proximal tip of the stent rests within the gastric lumen. Ring drainage allows future stent exchange easily and reduces the risk of stent-induced ductal change. Originally, transmural plastic stent deployment for EUS-PD might have had lesser migration into the abdominal cavity than EUS-guided hepaticogastrostomy because the pancreas and the gastric wall are in close contact. ${ }^{13}$ Particularly in cases in which the PD is not very dilated, plastic stents are more suitable than metallic stents. The rates of technical success and adverse events of EUS-PTS using plastic stents were reported to range from $80.9 \%$ to $100 \%$ and from $12.5 \%$ to $26.7 \%$, respectively. ${ }^{3,5,6,15,27}$ These immediate adverse events included abdominal pain, peritonitis, bleeding, pancreatic fluid collection, MPD leakage, and perforation. Matsunami et al. evaluated the usefulness of the $7 \mathrm{Fr}$ single pigtail type plastic stent (CX-T stent, TYPE IT; Gadelius Medical Co., Tokyo, Japan; Fig. 6), which has a total length of $20 \mathrm{~cm}$ and an effective length of $15 \mathrm{~cm}$, for EUS-PTS. ${ }^{6}$ The author discussed the length of the stent and stated that $15 \mathrm{~cm}$ was a suitable size for this stent in EUS-PTS.

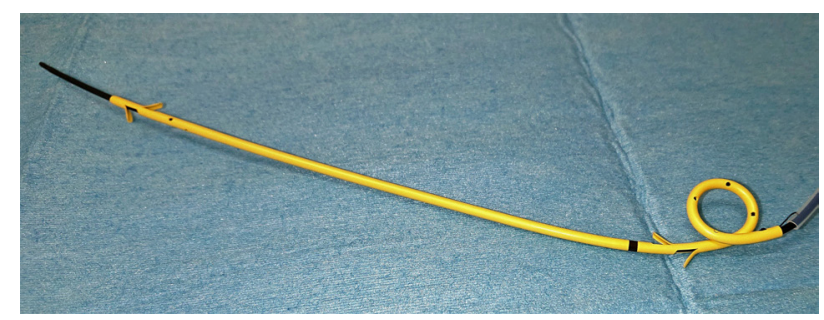

Fig. 6. TYPE IT (Gadelius Medical Co., Tokyo, Japan). This 7 Fr single pigtail type plastic stent has a total length of $20 \mathrm{~cm}$ and an effective length of $15 \mathrm{~cm}$. The length and a pigtail anchor together with its four flanges are effective in preventing stent migration.

Although the distal part of the stent was placed in the MPD, and two-thirds of the stent was retained on the stomach side, the long length was effective in preventing stent migration into the PD. A pigtail anchor together with its four flanges also prevented unnecessary migration. Indeed, there was no stent migration in that study. In addition, no pancreatic juice leakage was seen, probably because the stent had a side hole at the proximal and distal ends, but not in the middle part of the stent.

To overcome the disadvantage of transmural plastic stenting procedures in EUS-PD such as stent migration, stent placement failure, pancreatic juice leakage, and stent occlusion, a fully covered self-expandable metal stent (FCSEMS) was used as an alternative. Uncovered SEMSs are contraindicated because of the risk of pancreatic juice leakage and the difficulty in removing or replacing them due to tissue ingrowth. ${ }^{17} \mathrm{~A}$ large diameter FCSEMS might have the advantage of effective drainage and easy re-intervention compared to plastic stents. ${ }^{13}$ In addition, the tamponade effect of FCSEMS may prevent pancreatic juice leakage and reduce the bleeding risk associated with electrocautery tract dilation. Moreover, FCSEMS may provide extended stent patency, fewer repeat interventions, and shorter hospital stays. ${ }^{2,28}$ Oh et al., used a modified 6- or 8-mm FCSEMS (M.I. tech, Seoul, Korea) with blunt ends and anchoring flaps for EUS-PTS after failed ERCP in 25 patients with painful obstructive pancreatitis. ${ }^{29}$ The anchoring flaps of the FCSEMS with antimigration properties were designed to prevent proximal and distal migration. Stent placement was achieved in all patients with no severe or major adverse events. No stent occlusion, migration, and pancreatitis caused by cross-stream blockage were seen. Stent-induced ductal change after stent removal was also not observed. Oh et al. also assessed the outcomes of EUS-PTS using FCSEMS for pancreaticojejunal anastomosis strictures following Whipple procedures. ${ }^{2}$ Technical and clinical success were also both achieved in all the 20 cases, as well, in the above-mentioned study by the same team. Early adverse events with EUS-PTS 
using FCSEMS developed in three patients (15\%, 3/20), and all of them had mild self-limited abdominal pain. The favorable success and adverse event rates in the study were not inferior to those of plastic stents found in the previous study, but the evidence for EUS-PTS using FCSEMSs is limited. Indeed, Oh et al., stated that the results obtained using the FCSEMS might not be extrapolated to other FCSEMSs with different diameters and radial forces. ${ }^{2}$ However, further evaluation of FCSEMS use, especially a comparative study with a plastic stent, is necessary, Thus, EUS-PTS with an FCSEMS for MPD obstruction may be safe and feasible.

The indications for a lumen-apposing metal stent (LAMS), which was originally designed to provide solid anchorage between nonadherent luminal structures, have widened. It is now attributed to have effective roles in pancreatic cyst drainage, biliary drainage, and gastrojejunostomy. ${ }^{30}$ The structure of this stent is characterized by a fully covered dumbbell-shaped short stent made up of braided nitinol wire, which makes it possible to prevent tract leakage, migration, and tissue ingrowth and allows removability and trans-stent interventional procedures. Will et al. reported a case of EUS-PTS using LAMS (AXIOS; Boston Scientific) for a patient with recurrent episodes of severe chronic pancreatitis and retention of fluid in the PD against a background of pancreatolithiasis with ERCP failure. ${ }^{7}$ Since LAMS cannot be placed unless the PD is considerably dilated, the indications for using LAMS in EUS-PTS seem to be limited.

\section{Long-term outcomes of endoscopic ultrasound- guided pancreatic transmural stenting}

The long-term efficacy and safety of EUS-PTS have been studied, as well as the early and mid-term outcomes. Matsunami et al. reported in detail the long-term clinical outcomes after EUS-PTS, using plastic stents. ${ }^{6}$ For 25 patients who underwent successful EUS-PTS and could be followed-up, stent exchange was planned every 3-4 months during the year after initial stent placement, unless spontaneous dislodgement occurred. Four patients were stent-free 1 year after EUS-PTS as evinced from the improvement in their symptoms. Twelve patients who received regular stent exchange had no recurrence of symptoms. Further, in contrary to transpapillary PD, stenting under ERCP guidance was achieved in three patients. The leading late adverse events were stent dislodgement (24\%, $6 / 25)$, followed by recurrent pancreatitis $(8 \%, 2 / 25)$, within a median time of 23 months (range, 6-44 months). In this study, long-term clinical success was achieved in 92\% (23/25) of the total cases. In another study that evaluated EUS-PTS with plastic stents $(n=44)$, delayed adverse events such as stent blockage and spontaneous stent migration were seen in $12(31 \%)$ and five (13\%) subjects, respectively. ${ }^{15}$ In all patients who suffered from delayed adverse events, stent exchanges were attempted, which were carried out successfully in all the 17 cases. On the other hand, as per the long-term outcome of EUS-PTS with FCSEMS that was studied by Oh et al., 20 patients underwent EUS-guided transmural FCSEMS placement and were followed-up for a median of 27.2 months. During the follow-up period, late adverse events associated with the stent were seen in five (25\%) patients, including FCSEMS occlusion $(n=1)$, asymptomatic stent fracture at the gastric end $(n=3)$, and stent migration $(n=1)$. In particular, the patient with FCSEMS occlusion required stent revision. Stent fractures at the gastric end were reported to occur in patients who underwent an 8-cm stent deployment at 12.4, 21.9, and 46.4 months after EUS-PTS, respectively. Stent exchanges were performed in these three patients, although the remnant stents seemed to be functioning well as assessed by computed tomography imaging. Pancreatitis due to upstream or side-branch obstruction by FCSEMSs did not develop even in the long-term follow-up period. These reports suggest that the long-term outcomes of EUS-PTS are as favorable as the short and mid-term outcomes. Further evidence supporting the use of EUS-PTS with a longer follow-up period is required to establish the efficacy of the procedure.

\section{FUTURE PERSPECTIVE}

Although the outcomes of EUS-PD, as gauged from the previous studies, are favorable, there is still room for improvement as the rate of adverse events associated with EUS-PD is high. This is probably because EUS-PD is still at an early stage of development, and its strategies have not yet been established. If the techniques and devices for EUS-PD become standardized in the future, the outcomes could improve further. To this end, it is necessary to accumulate additional evidence in high-volume centers and develop dedicated devices. It will take some time before EUS-PD becomes widely accepted as a standard alternative to surgical or percutaneous drainage for patients with altered anatomy or with unsuccessful ERP.

\section{CONCLUSIONS}

The current study presents a comprehensive review on EUS-PD techniques, with a special focus on EUS-PTS. Since EUS-PD continues to be a challenging procedure with a high risk of adverse events, it should only be performed in selected patients by experienced personnel at high-volume centers. Further evidence from prospective controlled trials and appropriate devices to enhance the safety measures of this procedure are needed. 
Conflicts of Interest

The authors have no financial conflicts of interest.

Author Contributions

Supervision: Kazuhide Higuchi

Writing-original draft: Akira Imoto

Writing-review\&editing: Takeshi Ogura

ORCID

Akira Imoto: https://orcid.org/0000-0002-9353-7143

Kazuhide Higuchi: https://orcid.org/0000-0002-4142-2272

\section{REFERENCES}

1. Bataille L, Deprez P. A new application for therapeutic EUS: main pancreatic duct drainage with a "pancreatic rendezvous technique". Gastrointest Endosc 2002;55:740-743.

2. Oh D, Park DH, Song TJ, et al. Long-term outcome of endoscopic ultrasound-guided pancreatic duct drainage using a fully covered self-expandable metal stent for pancreaticojejunal anastomosis stricture. J Gastroenterol Hepatol 2020;35:994-1001.

3. Tessier G, Bories E, Arvanitakis M, et al. EUS-guided pancreatogastrostomy and pancreatobulbostomy for the treatment of pain in patients with pancreatic ductal dilatation inaccessible for transpapillary endoscopic therapy. Gastrointest Endosc 2007;65:233-241.

4. Hayat U, Freeman ML, Trikudanathan G, Azeem N, Amateau SK, Mallery J. Endoscopic ultrasound-guided pancreatic duct intervention and pancreaticogastrostomy using a novel cross-platform technique with small-caliber devices. Endosc Int Open 2020;8:E196-E202.

5. Uchida D, Kato H, Saragai Y, et al. Indications for endoscopic ultrasound-guided pancreatic drainage: for benign or malignant cases? Can J Gastroenterol Hepatol 2018;2018:8216109.

6. Matsunami Y, Itoi T, Sofuni A, et al. Evaluation of a new stent for EUS-guided pancreatic duct drainage: long-term follow-up outcome. Endosc Int Open 2018;6:E505-E512.

7. Will U, Reichel A, Fueldner F, Meyer F. Endoscopic ultrasonography-guided drainage for patients with symptomatic obstruction and enlargement of the pancreatic duct. World J Gastroenterol 2015;21:1314013151.

8. Fujii LL, Topazian MD, Abu Dayyeh BK, et al. EUS-guided pancreatic duct intervention: outcomes of a single tertiary-care referral center experience. Gastrointest Endosc 2013;78:854-864.e1.

9. Itoi T, Kasuya K, Sofuni A, et al. Endoscopic ultrasonography-guided pancreatic duct access: techniques and literature review of pancreatography, transmural drainage and rendezvous techniques. Dig Endosc 2013;25:241-252.

10. Itoi T, Yasuda I, Kurihara T, Itokawa F, Kasuya K. Technique of endoscopic ultrasonography-guided pancreatic duct intervention (with videos). J Hepatobiliary Pancreat Sci 2014;21:E4-E9.

11. Chen YI, Levy MJ, Moreels TG, et al. An international multicenter study comparing EUS-guided pancreatic duct drainage with enteroscopy-assisted endoscopic retrograde pancreatography after Whipple surgery. Gastrointest Endosc 2017;85:170-177.

12. Dhir V, Isayama $\mathrm{H}$, Itoi $\mathrm{T}$, et al. Endoscopic ultrasonography-guided biliary and pancreatic duct interventions. Dig Endosc 2017;29:472-485.
13. Ogura T, Ohama H, Higuchi K. Endoscopic ultrasound-guided pancreatic transmural stenting and transmural intervention. Clin Endosc 2020;53:429-435.

14. Ogura T, Nishioka N, Yamada M, Ueshima K, Higuchi K. Endoscopic ultrasound-guided pancreatic duct drainage using a fine-gauge balloon catheter. Endoscopy 2019;51:E145-E146.

15. Dalal A, Patil G, Maydeo A. Six-year retrospective analysis of endoscopic ultrasonography-guided pancreatic ductal interventions at a tertiary referral center. Dig Endosc 2020;32:409-416.

16. Mandai K, Uno K, Yasuda K. Endoscopic ultrasound-guided pancreatic duct drainage using a novel fine-gauge electrocautery dilator. Endoscopy 2019;51:E388-E389.

17. Krafft MR, Nasr JY. Anterograde endoscopic ultrasound-guided pancreatic duct drainage: a technical review. Dig Dis Sci 2019;64:1770-1781.

18. Honjo M, Itoi T, Tsuchiya T, et al. Safety and efficacy of ultra-tapered mechanical dilator for EUS-guided hepaticogastrostomy and pancreatic duct drainage compared with electrocautery dilator (with video). Endosc Ultrasound 2018;7:376-382.

19. Kitamura K, Yamamiya A, Ishii Y, Nomoto T, Honma T, Yoshida H. Electrocautery vs non-electrocautery dilation catheters in endoscopic ultrasonography-guided pancreatic fluid collection drainage. World J Gastrointest Endosc 2016;8:458-465.

20. Kahaleh M, Artifon EL, Perez-Miranda M, et al. Endoscopic ultrasonography guided biliary drainage: summary of consortium meeting, May 7th, 2011, Chicago. World J Gastroenterol 2013;19:1372-1379.

21. Fujii-Lau LL, Levy MJ. Endoscopic ultrasound-guided pancreatic duct drainage. J Hepatobiliary Pancreat Sci 2015;22:51-57.

22. Chapman CG, Waxman I, Siddiqui UD. Endoscopic ultrasound (EUS)-guided pancreatic duct drainage: the basics of when and how to perform EUS-guided pancreatic duct interventions. Clin Endosc 2016;49:161-167.

23. Park DH, Jang JW, Lee SS, Seo DW, Lee SK, Kim MH. EUS-guided biliary drainage with transluminal stenting after failed ERCP: predictors of adverse events and long-term results. Gastrointest Endosc 2011;74:12761284.

24. Khashab MA, Messallam AA, Penas I, et al. International multicenter comparative trial of transluminal EUS-guided biliary drainage via hepatogastrostomy vs. choledochoduodenostomy approaches. Endosc Int Open 2016;4:E175-E181.

25. Kanno Y, Ito K, Koshita S, et al. Efficacy of a newly developed dilator for endoscopic ultrasound-guided biliary drainage. World J Gastrointest Endosc 2017;9:304-309.

26. Amano M, Ogura T, Onda S, et al. Prospective clinical study of endoscopic ultrasound-guided biliary drainage using novel balloon catheter (with video). J Gastroenterol Hepatol 2017;32:716-720.

27. Tyberg A, Sharaiha RZ, Kedia P, et al. EUS-guided pancreatic drainage for pancreatic strictures after failed ERCP: a multicenter international collaborative study. Gastrointest Endosc 2017;85:164-169.

28. Park DH, Kim MH, Moon SH, Lee SS, Seo DW, Lee SK. Feasibility and safety of placement of a newly designed, fully covered self-expandable metal stent for refractory benign pancreatic ductal strictures: a pilot study (with video). Gastrointest Endosc 2008;68:1182-1189.

29. Oh D, Park DH, Cho MK, et al. Feasibility and safety of a fully covered self-expandable metal stent with antimigration properties for EUS-guided pancreatic duct drainage: early and midterm outcomes (with video). Gastrointest Endosc 2016;83:366-373.e2.

30. Bang JY, Varadarajulu S. Lumen-apposing metal stents for endoscopic ultrasonography-guided interventions. Dig Endosc 2019;31:619-626. 